\title{
Satisfaction with Primary Health Care in Patients with Upper Respiratory Tract Infection: A Three-Level Approach
}

\author{
Franziska Schoeni-Affolter Klazien Matter-Walstra Marcel Widmer André Busato
}

Institute for Evaluative Research in Orthopedic Surgery, MEM Center, University of Bern, Switzerland

\section{Key Words}

Alternative medicine - Complementary medicine - Patient satisfaction . Primary care - Upper respiratory tract infections

\section{Summary}

Background: Upper respiratory tract infections (URTI) are common conditions for which individuals seek health care. The present study analyzes the satisfaction of URTI patients with general practitioners offering conventional treatment, alternative treatment, or a combination of both. Patients and Methods: $\mathrm{Pa}$ tients' satisfaction with care was evaluated based on concepts of structure, process and outcome. Data were drawn from a nationwide cross-sectional survey, conducted in Switzerland, which evaluated conventional (COM) and complementary and/or alternative medicine (CAM). Participating physicians provided information about care structure. A questionnaire filled in by doctors and patients in parallel during the first visit provided information about the process of care (e.g. patients' general health, duration and severity of symptoms, co-morbid conditions, diagnostic/therapeutic procedures and consultation time). One month later, patients completed a second questionnaire on their subjective disease- and treatment-related health status, beliefs and fulfilment of expectations, and treatment effects (outcome). Results: Structural and procedural differences were found. The most striking was the significantly longer consultation time with CAM physicians. Patients' satisfaction as an outcome variable, however, did not differ between the different treatment approaches. Conclusions: General practitioners, offering a variety of treatments, accommodate an important demand in primary health care. Regardless of differences in structure and procedure of the practice types, patients perceive equal benefits of treatment after one month. Nonetheless, possible long-term effects of longer consultations in CAM practices, such as a possibly more stable long-term amelioration of health, have to be carefully evaluated in future studies with the same study design.

\author{
Schlüsselwörter \\ Alternativmedizin · Komplementärmedizin . \\ Patientenzufriedenheit - Medizinische Grundversorgung · \\ Infektionen der oberen Atemwege
}

\section{Zusammenfassung}

Hintergrund: Infektionen der oberen Atemwege sind häufige Erkrankungen, die zum Arztbesuch führen. Die vorliegende Studie untersucht die Zufriedenheit von Patienten mit Infektionen der oberen Atemwege mit der medizinischen Grundversorgung in Form von konventioneller und/oder alternativer Therapie. Patienten und Methoden: Basierend auf dem Konzept von Struktur, Prozess und Ergebnis wurde die Patientenzufriedenheit mit der Versorgung durch Ärzte mit konventionellem und/oder alternativem Behandlungsansatz evaluiert. Die Daten stammen aus einer schweizerischen Querschnittsstudie, welche konventionelle Arztpraxen (COM) mit solchen, die alternative Medizin (CAM) anbieten, vergleicht. Die beteiligten Ärzte lieferten Informationen über die Struktur der Versorgung. Fragebögen, die von Arzt und Patient beim ersten Besuch parallel ausgefüllt wurden, lieferten Angaben über Behandlungsprozesse (z.B. allgemeiner Gesundheitszustand des Patienten, Dauer und Schwere der Symptome, zusätzliche Erkrankungen sowie diagnostisch/therapeutische Verfahren und Behandlungsdauer). Die Patienten füllten einen Monat später einen zweiten Fragebogen aus, der die Patientenzufriedenheit mit dem subjektiven krankheits- und therapiebezogenen Gesundheitsstatus, ihre Vorstellungen und die Erfüllung ihrer Erwartungen und die Behandlungserfolge erfasste. Ergebnisse: Strukturelle und prozessorientierte Unterschiede zwischen den Behandlungsansätzen wurden gefunden. Am auffälligsten war die signifikant längere Konsultationsdauer beim CAM-Arzt. In Bezug auf die Patientenzufriedenheit als Zielgröße konnten keine Unterschiede zwischen den Behandlungsansätzen festgestellt werden. Schlussfolgerungen: Die Allgemeinmedizin, die in der Schweiz viele verschiedene Behandlungsarten umfasst, befriedigt eine wichtige Nachfrage in der medizinischen Grundversorgung. Trotz struktureller und prozessorientierter Unterschiede scheinen die Patienten die verschiedenen Behandlungsarten nach einem Monat als gleich gut einzuschätzen. Jedoch müssen weitere Studien mögliche Langzeiteffekte wie eine möglicherweise stabilere Verbesserung der Gesundheit, die aus längerer Konsultationsdauer beim CAM-Arzt resultieren könnte, mit demselben Studiendesign untersuchen.

\begin{tabular}{ll}
\hline KARGER & @ 2007 S. Karger GmbH, Freiburg \\
Fax +49 761 4520714 & Accessible online at: \\
$\begin{array}{l}\text { E-mail Information@Karger.de } \\
\text { www.karger.com }\end{array}$ & www.karger.com/fok
\end{tabular}

Dr. Franziska Schoeni-Affolter Institut für Evaluative Forschung in orthopädischer Chirurgie MEM Center, Universität Bern Stauffacherstr. 78, 3014 Bern, Switzerland Tel. +41 31 63159-65, Fax -61

E-mail franziska.schoeni@memcenter.unibe.ch 


\section{Introduction}

In view of expensive health care systems with finite resources and rising expectations, treatment evaluations have become more and more important. Due to the fact that in Europe and in the United States an increasing number of patients seek various methods of alternative medical treatments [1,2], the Swiss government decided in 2002 to evaluate five methods of alternative and complementary medicine (CAM) - homeopathy, anthroposophy, neural therapy, herbal medicine, and traditional Chinese medicine - which had been provisionally included in the basic health insurance in 1998 for a period of 5 years. Funded by the Swiss Federal Office of Public Health, a nationwide cross-sectional evaluation was performed to compare alternative and conventional treatment methods [3]. Although there is much debate about how quality of care should be measured, levels of user satisfaction are highly relevant signals as they reflect the consumers' perceptions of the standards achieved [4, 5]. Studies have shown that, basically, satisfaction can be related to patient demographics [6], patients expectations [5], time spent with the physician, and also to an individual's satisfaction with life in general [7]. As part of this project, the aim of our study was to evaluate patients' satisfaction under the specific medical condition of upper respiratory tract infections (URTI), known to be a common but not life-threatening reason for consulting a general practitioner. Thereby, a 3-level analysis (structure, process and outcome) [8,9] was performed to evaluate if structural variables on the physician's side and/or the process of care with demographic and healthrelated variables among patients diagnosed with URTI are associated with the degree of treatment satisfaction and the fulfilment of expectations under different treatment approaches.

\section{Materials and Methods}

The data for this study are drawn from a nationwide cross-sectional survey in Switzerland that evaluated the use of conventional and/or alternative treatment in primary care [3]. The project was designed based on the concepts of structure, process and outcome, the latter including 2 components: intervention and interaction-related outcome.

All certified physicians for alternative therapies - including homeopathy, anthroposophy, neural therapy, phytotherapy, or traditional Chinese medicine (according to the Swiss Medical Association [FMH]) - were invited to participate. Additionally, a random sample of primary care physicians not certified in any medical CAM discipline was asked to participate. The participating physicians were divided into 3 groups according to self-declared medical activity and professional qualification (list provided by FMH):

- Certified CAM physicians (CAM+): physicians who perform complementary and alternative medicine with certificates provisionally recognized by basic health insurers and with expenditures for CAM reimbursed.

- COM physicians: physicians who perform solely conventional medical procedures.

- Non-certified CAM physicians (CAM-): physicians who perform conventional and alternative procedures without approved certification in CAM according to their own declaration and without reimbursement of expenditures for CAM by basic health insurances.

In a first step, the structure of care was evaluated among the 3 groups of participating physicians. Then, for the evaluation of processes of the provided care, the practitioners recruited patients attending their practice on specific days $[3,10]$. A first sampling took place in the waiting room prior to the consultation. By use of questionnaires the patients, who participated on a voluntary basis, were asked their demographic and educational status and the severity of their complaints. In parallel, the physicians completed a questionnaire on each participating patient. Answers were given concerning patients' general health, duration and severity of his symptoms, main diagnoses and co-morbid conditions, diagnostic and therapeutic procedures. The latter were assessed and classified into 4 groups: 'conventional', 'alternative', 'combined treatment' and 'other/none.' Due to the fact that consultation time alone may already be associated with the degree of patient satisfaction $[6,11,12]$, physicians were asked the duration of each consultation. Criteria for the inclusion of physicians (whether $\mathrm{COM}, \mathrm{CAM}-$, or $\mathrm{CAM}+$ ) in the study were working at least 2 days a week as primary care providers, and for the inclusion of patients: age $>16$ years and being diagnosed by their physicians with URTI according to the ICD-10 classification ( $\mathrm{J} 00$ = acute rhinopharyngitis, $\mathrm{J} 01=$ acute sinusitis, $\mathrm{J} 02$ = acute pharyngitis, $\mathrm{J} 03$ = acute tonsillitis, $\mathrm{J} 04$ = acute laryngitis or tracheitis, J05 = acute obstructive laryngitis or epiglottitis, J06 = acute infection on several sites). Study design and data management ensured that the physicians remained unaware of the patients' answers. Physicians were reimbursed with 500,- SFR (approximately 330,- EUR) for their expenditures.

A second sampling among the patients followed 1 month later by sending a questionnaire to the patients' home addresses inquiring into their perception of disease- and treatment-related health status, beliefs and fulfilment of expectations, and treatment effects, thereby measuring intervention-related outcome. General patient satisfaction with their doctor was assessed with the same questionnaire used by the survey conducted by the European Task Force on Patient Evaluations of General Practice (EuroPEP) [11]. The EuroPEP questionnaire provides information on what patients expect of and value in general practice care and refers to interaction-related outcome. All of the 23 questions have a 5-point answer scale ranging from poor to excellent and cover the following dimensions:

- relation and communication (6 questions),

- medical care (5 questions)

- information and support (4 questions),

- continuity and cooperation (2 questions),

- facilities availability and accessibility (6 questions).

Mental and physical components of health measures were explored with the SF-36 questionnaire [13], which is a widely used instrument in health service research to assess health-related quality of life. The validity and reliability of this instrument has been established for measuring quality of life in large populations of both healthy and diseased individuals. The goal was to obtain valid estimates of physical and mental well-being in the study population in order to scale potential differences of outcomes. The SF-36 data were therefore not considered as an outcome but as attributes of patient populations.

For the analysis of the data the patients were grouped according to the physicians' indications about possible diagnoses beyond URTI, since comorbidity influences the degree of satisfaction with the primary care service $[6,14]$. Co-morbidity was defined as having one or more diagnoses in addition to the main diagnosis of URTI. Assuming that patients with complex and/or chronic conditions require longer consultations to allow adequate time for the review of their illness and treatment, as well as an opportunity to raise issues and concerns about their illness, its impact on their lives, and their personal management strategies, the chronicity of the disease state was asked. Health problems of the upper respiratory tract lasting $>3$ months before the analyzed consultation (self-declared in the consultation questionnaire) were classified as chronic, and those lasting $\leq 3$ months were categorized as acute. 
Table 1. Characteristics of physicians' population (structure)

\begin{tabular}{|c|c|c|c|c|c|c|c|}
\hline & \multirow{2}{*}{$\begin{array}{l}\text { Total } \\
\%\end{array}$} & \multicolumn{2}{|l|}{$\mathrm{COM}$} & \multicolumn{2}{|c|}{ CAM- } & \multicolumn{2}{|c|}{$\mathrm{CAM}+$} \\
\hline & & $\%$ & $95 \% \mathrm{CI}$ & $\%$ & $95 \% \mathrm{CI}$ & $\%$ & $95 \% \mathrm{CI}$ \\
\hline Responders & & 33.6 & $24.8-42.4$ & 40.7 & $28.6-52.9$ & 56.8 & $35.8-50.7$ \\
\hline Female doctors* & 18.4 & 7.6 & $0.4-14.6$ & 20.0 & $8.9-31.1$ & 23.1 & $15.0-31.2$ \\
\hline X-ray* & 51.7 & 83.0 & 72.9-93.2 & 68.0 & $55.1-80.9$ & 27.9 & $19.4-37.5$ \\
\hline Ultrasound* & 22.2 & 18.9 & $8.3-29.4$ & 40.0 & $26.4-53.6$ & 15.4 & $9.1-23.8$ \\
\hline Echo cardiograph* & 88.4 & 100 & & 94.0 & $87.4-100$ & 79.8 & $70.8-87.0$ \\
\hline \multirow[t]{2}{*}{ Lab analysis* } & 86.5 & 98.1 & $94.4-100$ & 92.0 & $80.8-97.8$ & 77.8 & $68.7-85.9$ \\
\hline & & Mean & $95 \% \mathrm{CI}$ & Mean & $95 \%$ CI & Mean & $95 \% \mathrm{CI}$ \\
\hline \multicolumn{2}{|l|}{ Age of doctors, years } & 52.2 & $50.2-54.1$ & 49.0 & $47.3-51.4$ & 51.0 & $50.1-52.7$ \\
\hline \multicolumn{2}{|c|}{ Number of URTI patients treated } & 2.3 & & 2.16 & & 1.78 & \\
\hline
\end{tabular}

*Significantly different distribution $(\mathrm{p}<0.05)$.

Table 2. Demographic attributes and perceived health status of patients (process)

\begin{tabular}{|c|c|c|c|c|c|c|c|}
\hline & \multirow{2}{*}{$\begin{array}{l}\text { Total } \\
\%\end{array}$} & \multicolumn{2}{|l|}{$\mathrm{COM}$} & \multicolumn{2}{|c|}{ CAM- } & \multicolumn{2}{|c|}{$\mathrm{CAM}+$} \\
\hline & & $\%$ & $95 \% \mathrm{CI}$ & $\%$ & $95 \%$ CI & $\%$ & $95 \% \mathrm{CI}$ \\
\hline Proportion of responders to second questionnaire after one month* & 45.8 & 33.6 & $24.8-42.4$ & 40.8 & $28.6-52.9$ & 56.8 & $49.3-64.2$ \\
\hline Proportion of female patients & 72.1 & 61.0 & $46.6-75.3$ & 75.0 & $64.2-85.8$ & 75.2 & $66.6-83.8$ \\
\hline Education: proportion of patients with university degree & 30.5 & 29.3 & $13.3-46.8$ & 22.7 & $9.8-35.6$ & 34.3 & $24.7-43.8$ \\
\hline General health: very good or excellent (5-point scale $\left.{ }^{a}\right)$ & 37.9 & 46.3 & $23.1-69.5$ & 43.2 & $25.7-62.5$ & 32.4 & $19.4-45.4$ \\
\hline Serious symptoms (3-point scale $\left.{ }^{b}\right)$ & 22.7 & 18.9 & $4.7-33.0$ & 18.4 & 4.9-31.9 & 25.7 & $17.5-33.9$ \\
\hline Degree of disorder: strong or very strong (5-point scale ${ }^{c}$ ) & 4.7 & 4.8 & $0-7.3$ & 4.5 & $0-13.5$ & 5.7 & $0.6-10.9$ \\
\hline Proportion of chronic patients* & 18.9 & 19.5 & $8.3-30.7$ & 4.6 & $0-10.8$ & 26.0 & $15.8-33.7$ \\
\hline Proportion of co-morbidities $(\geq 1)$ & 22.1 & 29.3 & $16.3-42.2$ & 18.2 & $6.8-29.6$ & 21.0 & $10.9-31.0$ \\
\hline \multirow[t]{2}{*}{ Proportion of applied conventional therapy* } & 38.9 & 95.1 & $88.3-100$ & 47.7 & $27.0-68.4$ & 13.3 & $5.9-20.7$ \\
\hline & Mean & Mean & & Mean & & Mean & \\
\hline Age of patients, years & 42.6 & 43.1 & & 39.7 & & 42.0 & \\
\hline
\end{tabular}

${ }^{a}$ Excellent - very good - good - mediocre - bad.

${ }^{\mathrm{b}}$ Serious - mediocre - marginal.

${ }^{\mathrm{c}}$ Weak - rather weak - mediocre -strong - very strong.

*Significantly different distribution $(\mathrm{p}<0.05)$

Data Management and Data Analysis

All data were recorded using a relational database. Forms filled in by patients and physicians during consultations were coded and recorded manually. Questionnaires mailed to patients 1 month after the initially recorded consultation were designed to be machine readable and were recorded by the Swiss Federal Office of Information Technology using OCR procedures.

Data analysis was performed in 2 steps. A first step included descriptive analyses using tables and graphs. Analytical procedures were applied in a second step. Differences between groups for age, consultation time and SF-36 data were analyzed with multivariate linear models. Ordinal outcomes were reduced to 2-level scales with the most favourable answer category coded as 1 (in health status and degree of disorder, the two most favourable answers were coded as one) and all other non-missing categories as 0 . These data were analyzed using multivariate logistic regression models. Co-variables of multivariate models were defined a priori and were aimed towards adjusting for demographic factors of the patients (age and gender). All analytical procedures accounted for clustering of observations at the practice level using Taylor series expansion procedures for the $2 \times 2$ tables and mixed effects, hierarchical models for multivariate procedures $[15,16] .95 \%$ confidence intervals $(95 \% \mathrm{CI})$ of means, proportions and odds ratios were calculated accordingly.

\section{Results}

The data for this study derived from a cross-sectional survey including 360 practices and 11,932 adult patients ( $>16$ years) seeking conventional and/or complementary primary care. Most patients were diagnosed with musculoskeletal disorders 


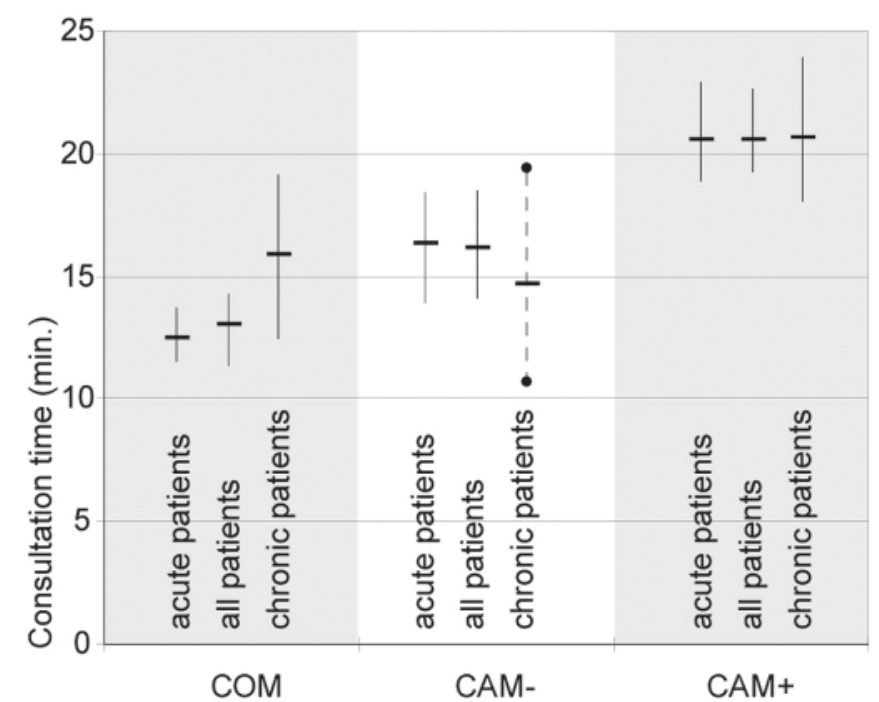

Fig. 1. Consultation time. Box plot of mean consultation time (min) and the $95 \% \mathrm{CI}$ in the 3 practice types for acute, all and chronic patients with a significant difference in consultation time between $\mathrm{COM}$ and $\mathrm{CAM}+$ physicians ( $\mathrm{n}=190$ patients).

(16\%) followed by patients with cardiovascular diseases $(15.8 \%)$. Diseases of the respiratory system were diagnosed in 1,097 patients $(10.7 \%)$, of whom $415(37.8 \%)$ were treated by $207 / 360$ physicians for URTI. $190 / 415$ (45.8\%) patients responded to the second questionnaire and were included in the study.

Characteristics of Physicians and Practices (Structure of Care) The evaluation of the physicians' sample $(n=207)$ showed no differences in the mean age and years since graduation. There was no significant difference in the number of patients treated among the 3 groups, but significantly more female practitioners were found in the CAM physician group. Noteworthy is the significantly broader technical equipment of COM practices (table 1).

\section{Demographic Attributes and Perceived Health Status of the Patients (Process of Care)}

Of the 415 patients who had filled in the first questionnaire 190 also answered second questionnaire 1 month later and were included in the study. Significantly more patients from the CAM+ group than from the other two groups returned the second questionnaire. Basic demographic and health status data of the included patient population are given in table 2. The patients of the different practice types (COM, CAM-, $\mathrm{CAM}+$ ) showed no significant differences in distribution of age and gender or in educational levels. General health, severity of symptoms and the degree of disorder were perceived as equal across the patient groups. Age- and gender-adjusted odds ratios for these variables yielded no significant differences between the groups, although age appeared to be a significant factor $(\mathrm{p}=0.049)$ for general health status. Significant differences were found in the duration of health problems. Considerably more patients of CAM + physicians stated that their health problems lasted longer than 3 months $(\mathrm{p}=0.014)$. Possible factors which could influence chronicity as the dependent variable were analyzed in a random effects model. The practice type acted as a significant effect. Those physicians offering COM see significantly fewer chronic patients than those physicians offering CAM+ $(\mathrm{p}=0.0166)$ but more than the CAM- physicians $(\mathrm{p}=0.0192)$. The only additional variable with a significant effect to the chronic state was patient's age ( $p=0.0138)$, with older patients obviously being more likely to be chronically ill than younger patients. Patient gender had no influence on chronicity. No significant differences were observed in the age- and gender-adjusted physical and mental health scores (from the SF-36 questionnaire).

\section{Diagnostic and Therapeutic Attributes of Consultations (Processes of Care)}

The diagnostic and therapeutic procedure was investigated with the physicians' questionnaire. Consultation frequencies showed a clear seasonal peak in winter without significant differences between groups. $24.5 \%$ of all consultations were considered by physicians as emergencies; no significant differences between groups were observed here.

Considerable differences between groups were observed in the duration of consultations (fig. 1). A subsequent analysis across treatment modalities indicated that very long consultations were particularly observed for homeopathic treatments ( $25 \%$ of consultations in this group lasted $>25 \mathrm{~min}$ ). As such long consultations are not uncommon in homeopathy, they could not simply be declared as outliers; log-transformed consultation times comprising the full dataset were thus used for subsequent statistical analyses. Age- and gender-adjusted consultations with CAM+ physicians $(\mathrm{LSM}=19.5 \mathrm{~min})$ lasted significantly longer $(\mathrm{p}=0.0264)$ than consultations with COM physicians $(\mathrm{LSM}=15.58), \mathrm{CAM}-$ falls in between $(\mathrm{LSM}=$ $16.7 \mathrm{~min}$ ) and is not significantly different from COM. Additional co-factors such as chronicity or the interaction between chronicity and the practice type showed no significant effect. The analysis of the therapeutic procedures revealed that COM physicians employ conventional therapy in 95\% $(n=39)$ of their consultations. Only rarely $(\mathrm{n}=2)$ do COM physicians solely use alternative or combined conventional and alternative therapies. CAM+ physicians apply conventional therapy in only $13.3 \%(n=14)$ of their cases, while a combination of conventional and alternative therapy was used in $10.5 \%$ ( $\mathrm{n}=$ 11). In $76 \%(n=80)$ of the cases CAM+ physicians used alternative therapy alone. The use of alternative treatments by CAM- physicians falls between that of COM and CAM+ physicians.

\section{Outcome Variables}

Intervention-related outcome variables such as symptom resolution, treatment satisfaction and treatment success, side ef- 
Table 3. Outcome variables (interventionrelated)

\begin{tabular}{|c|c|c|c|c|c|c|c|}
\hline & \multirow{2}{*}{$\begin{array}{l}\text { Total } \\
\%\end{array}$} & \multicolumn{2}{|c|}{$\mathrm{COM}$} & \multicolumn{2}{|c|}{ CAM- } & \multicolumn{2}{|c|}{$\mathrm{CAM}+$} \\
\hline & & $\%$ & $95 \% \mathrm{CI}$ & $\%$ & $95 \% \mathrm{CI}$ & $\%$ & $95 \% \mathrm{CI}$ \\
\hline \multicolumn{8}{|l|}{ Symptom resolution } \\
\hline $\begin{array}{l}\text { Treatment satisfaction } \\
\quad\left(4 \text {-point scale }{ }^{b}\right)\end{array}$ & 60.9 & 73.1 & $58.1-88.2$ & 61.0 & $44.0-75.1$ & 56.4 & $46.3-66.6$ \\
\hline $\begin{array}{l}\text { Treatment success } \\
\left(3 \text {-point scale }{ }^{c}\right)\end{array}$ & 65.2 & 71.8 & $56.2-87.4$ & 65.9 & $53.2-78.6$ & 62.5 & $53.0-71.9$ \\
\hline $\begin{array}{l}\text { Treatment side effect } \\
\text { Other treatment } \\
\text { effects (positive) }\end{array}$ & 21.9 & 10.2 & $0.9-19.5$ & 11.4 & $1.4-21.4$ & 26.5 & $16.4-36.5$ \\
\hline $\begin{array}{l}{ }^{\mathrm{a}} \text { Resolved - almost re } \\
\text { b } \mathrm{High}-\text { positive - neg } \\
{ }^{\mathrm{c}} \text { Good - mediocre - li }\end{array}$ & $\begin{array}{l}\text { ved - } \\
\text { ve }-n \\
\text { e. }\end{array}$ & $\begin{array}{l}\text { ker - } \\
\text { all. }\end{array}$ & langed. & & & & \\
\hline
\end{tabular}

fects of treatment, and other treatment effects were assessed. Neither of these outcome variables showed a significant difference when expressed as age- and gender-adjusted odds ratios of the most favourable outcome of COM compared to $\mathrm{CAM}-$ or $\mathrm{CAM}+$ physicians. Table 3 includes the respective intervention-related outcomes (in \%) of the 3 groups. The interaction-related outcome assessed with the EuroPEP questionnaire yielded minimal differences among the 3 groups for all of the 5 dimensions evaluated when assessed in the same manner (fig. 2). Only one question (no. 15: Helping you understand the importance of following his or her advice?) concerning the dimension 'Information and support' and one question on 'Facilities availability and accessibility' (no. 20: Getting through to the practice on telephone?) revealed a significant difference in favour of COM versus CAM+ physicians. Two other questions, one in the dimension 'Communication and relation' (no. 3: Making it easy for you to tell him or her about your problem?) and one in 'Information and support' (no. 14: physician explains well the importance of following the advice) were answered more favourably for CAMphysicians versus COM physicians.

\section{Discussion}

This study evaluated the quality of care for patients suffering from URTI and treated with conventional and/or alternative methods. The study design was based on the concept of structure (input), process, and outcome [8] and focused on individual users. The results showed significant differences in structure and process of care in the three practice settings of COM, CAM-, or CAM+ physicians. However, no significant differences in patient' satisfaction as outcome variable was found. Structure referring to resource and doctors' characteristics as conduits through which care is delivered yielded differences in technical equipment. Obviously, alternative and complementary trained physicians use fewer technical diagnostic devices like x-ray, ultrasound or lab analysis. We found, consistent with the current literature [17-19], proportionally more female physicians predisposed to CAM than their colleagues in the COM group. Additionally, this pattern of more female physicians in less technically equipped practices can be due to the fact that female doctors tend to have a different focus on patients with more psychosocial, behavioural and metabolic disorders [20,21], where technical equipment is not of paramount importance.

Process of care, the actual care given, with demographic and health-related characteristics of patients as well as the actual consultation time, which is thought to serve as a therapeutic and diagnostic attribute in the process of care, showed differences as well. CAM+ users are more chronically ill as compared to CAM- and COM users. This may indicate that chronically ill patients look for alternative treatments because conventional treatments have kept failing. A recent study of the US population showed that higher income, which partially runs in parallel with higher education, and female gender are further determining factors for choosing a CAM+ physician [22]. Our study tends to result in higher proportions of better educated and more female patients as CAM+ users; the distribution, however, is not significantly different in the 3 groups after correction for the other factors. This finding is probably due to the fact that URTI is a common but mostly self-limiting disease [23] with well-established conventional and/or alternative treatment approaches [24]. In terms of the number of co-morbid conditions, our data provide no indication that $\mathrm{CAM}+$ physicians treated more patients with complex health problems than CAM- or COM physicians. Concerning the therapeutic and diagnostic attributes of the process of care, the significantly longer consultation times of CAM+ physicians were striking, irrespective of the patient's chronic state of the disease or the co-morbidity.

Outcome refers to quality of care as a consequence of structural and procedural attributes. Intervention-related quality of care refers to the perceived treatment efficacy in terms of 
Fig. 2. Results of the EuroPEP questionnaire. Odds ratios of EuroPEP questions: Comparison between most favourable answers of COM to $\mathrm{CAM}-$ and $\mathrm{COM}$ to $\mathrm{CAM}+$, respectively, for 23 questions.

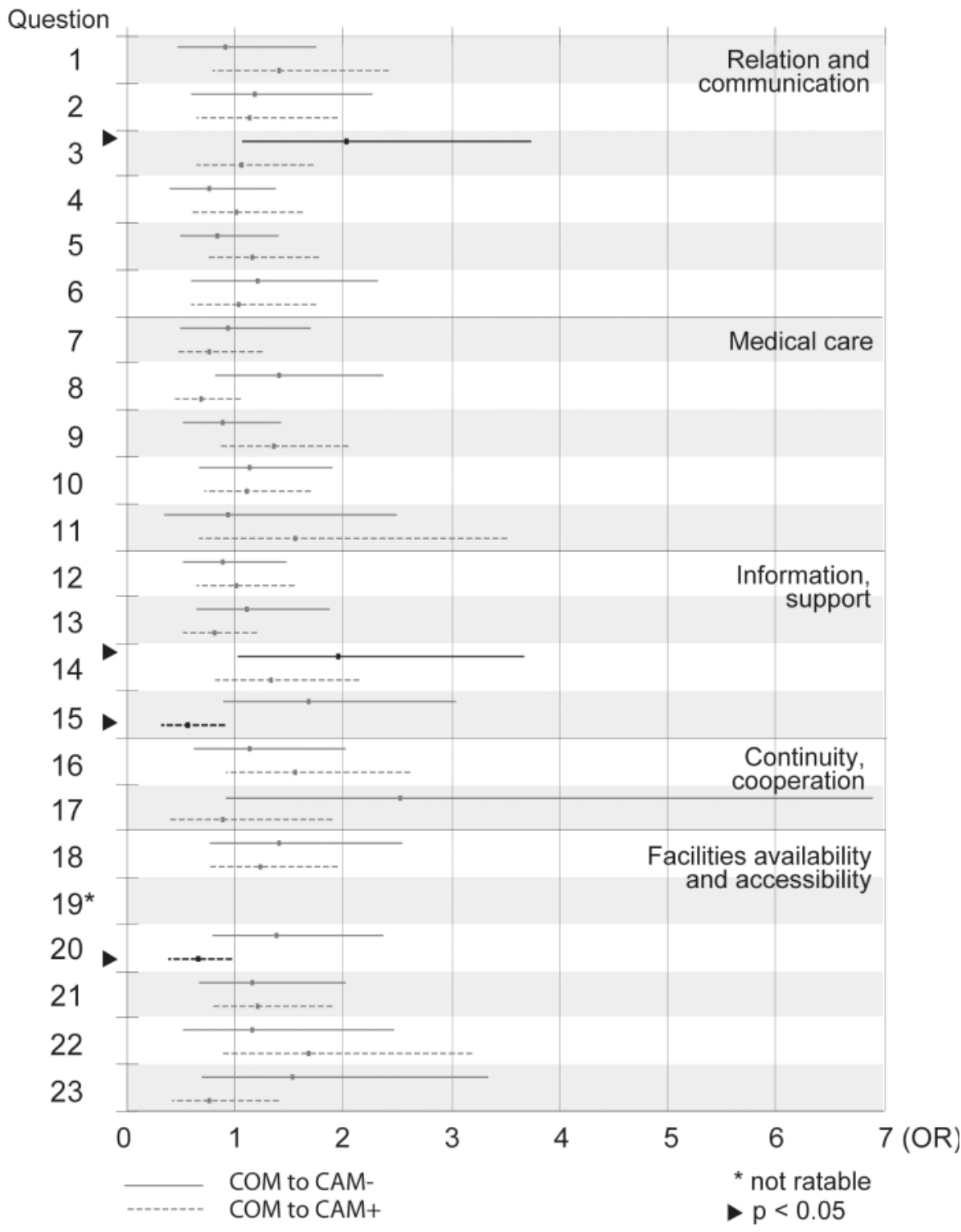

matched expectations of treatment results, symptom relief, and frequency of adverse side effects. The evaluation of interaction between patient and physician is based on the individual perception of what occurred during a consultation. After 1 month, the patients of the 3 groups were equally satisfied with the intervention-related quality of care as well as with the evaluated interaction in terms of the 5 dimensions of the EuroPEP questionnaire. We must assume that they have clearly defined preferences about the characteristics of the care provided. However, longer consultation times in CAM+ practices did not automatically result in better outcomes in terms of quality of care [25]. The quality of time spent with the physician seems to matter more than its quantity, at least regarding a diagnostic group, which is known to have a predominant natural course with rapid restitution after a few weeks/days, mostly unaffected by any medical intervention. The study therefore shows that none of the practice types has a monopoly on high quality care according to the patients' judgments: different types of treatment may have different strengths [6]. Purely economic considerations suggest that $\mathrm{CAM}+$ physicians can limit their consultation times, especially for often acute, minor illnesses such as URTI. Patients with acute URTI need to have access to quick and simple services and advice appropriate for this indication [26]. Yet, possible long-term effects in terms of less chronification or fewer recurrent infections, which could possibly result from longer consultation times, in which patients are encouraged to control their own health care decision, was not assessed due to the short time window of 1 month. Additional research with stratifications according to the applied therapies and longer time windows is needed to determine if the significantly longer consultations in $\mathrm{CAM}+$ practices lead to what has been described as patient 'enablement' [27], better compliance, and prevention. 


\section{Limitations and Strengths}

The results of our study are limited by the restriction of the sampling frame as being a part of a health technology assessment (HTA) project to evaluate the health status and health care utilization of patients in complementary and conventional primary care in Switzerland. There was no intention to study the effectiveness of one single treatment. Outcomes were solely based on patient perceptions. Further limitations common to this type of research refer to selection bias of physicians who voluntarily participated in the project and response bias of patients who decided to complete the questionnaires.

Strengths of the study are related to the fact that physicians shared the same biomedical background: all physicians were trained and certified in conventional medicine, and EuroPEP as an extensively validated patient satisfaction instrument was used to assess the quality of physician-patient relationship. Because COM physicians applied conventional therapy in $>95 \%$ of cases, and CAM+ physicians employed alternative treatment in $86 \%$ of all consultations, physicians and their treatment applications are well characterized by the COM, CAM-, and CAM+ designations.

\section{Conclusions}

The results of this study show no difference in patient-based evaluation of satisfaction with care under conventional, alternative, or combined treatment for URTI. Physicians with an alternative approach spent significantly more time with their patients, irrespective of chronicity or co-morbidity, without an additional patient-perceived short-term benefit. Even though the challenge to physicians of optimizing clinical success and controlling costs in an expensive health care system with rising expenditures must remain, the long-term outcome of patients with longer consultations in CAM practices resulting in potentially stable long-term health amelioration with reduced use of medication, and in the end, resulting in a less expensive health system, remain to be evaluated in future studies.

\section{References}

1 Eisenberg DM, Davis RB, Ettner SL, Appel S, Wilkey S, Van Rompay M, Kessler RC: Trends in alternative medicine use in the United States, 1990-1997: results of a follow-up national survey. Jama 1998;280:1569-1575.

2 Fisher P, Ward A: Complementary medicine in Europe. BMJ 1994;309:107-111.

3 Melchart D, Mitscherlich F, Amiet M, Eichenberger R, Koch P: Programm Evaluation Komplementärmedizin (PEK) Schlussbericht. 2005, www.bag.admin.ch/themen/krankenversicherung/ (siehe Archiv 2005).

4 Isenberg SF, Stewart MG: Utilizing patient satisfaction data to assess quality improvement in community-based medical practices. Am J Med Qual 1998; 13:188-194.

5 Jackson JL, Chamberlin J, Kroenke K: Predictors of patient satisfaction. Soc Sci Med 2001;52: 609-620.

6 Campbell SM, Hann M, Hacker J, Burns C, Oliver D, Thapar A, Mead N, Safran DG, Roland MO: Identifying predictors of high quality care in English general practice: observational study. BMJ 2001;323:784-787.

7 Weiss GL: Patient satisfaction with primary medical care. Evaluation of sociodemographic and predispositional factors. Med Care 1988;26:383-392.

8 Campbell SM, Roland MO, Buetow SA: Defining quality of care. Soc Sci Med 2000;51:1611-1625.

$\checkmark$ Donabedian A: The quality of care. How can it be assessed? Jama 1988;260:1743-1748.

10 Busato A, Donges A, Herren S, Widmer M, Marian F: Health status and health care utilisation of patients in complementary and conventional primary care in Switzerland - an observational study. Fam Pract 2006;23:116-124.
Grol R, Wensing M, Mainz J, Ferreira P, Hearnshaw H, Hjortdahl P, Olesen F, Ribacke M, Spenser T, Szecsenyi J: Patients' priorities with respect to general practice care: an international comparison. European Task Force on Patient Evaluations of General Practice (EUROPEP). Fam Pract 1999;16: 4-11.

12 Wensing M, Grol R, Asberg J, van Montfort P, van Weel C, Felling A: Does the health status of chronically ill patients predict their judgements of the quality of general practice care? Qual Life Res 1997;6:293-299.

13 Ware JE Jr, Sherbourne CD: The MOS 36-item short-form health survey (SF-36). I. Conceptual framework and item selection. Med Care 1992;30: 473-483.

14 Sinikallio S, Aalto T, Airaksinen O, Herno A, Kroger H, Savolainen S, Turunen V, Viinamaki H: Somatic comorbidity and younger age are associated with life dissatisfaction among patients with lumbar spinal stenosis before surgical treatment. Eur Spine J 2007;16:857-64.

15 Sheu CF: Fitting mixed-effects models for repeated ordinal outcomes with the NLMIXED procedure. Behav Res Meth Instrum Comput 2002;34:151-157.

16 Singer J: Using SAS PROC MIXED to fit multilevel models, hierarchical models, and individual growth models. J Educ Behav Stat 1998:23;323-355.

17 Bensing JM, van den Brink-Muinen A, de Bakker DH: Gender differences in practice style: a Dutch study of general practitioners. Med Care 1993;31: 219-229.

18 Britt H, Bhasale A, Miles DA, Meza A, Sayer GP, Angelis M: The sex of the general practitioner: a comparison of characteristics, patients, and medical conditions managed. Med Care 1996;34:403-415.

19 Widmer M, Herren S, Donges A, Marian F, Busato A: Complementary and conventional medicine in Switzerland: comparing characteristics of general practitioners. Forsch Komplementärmed 2006;13: 234-240.
20 Kurtz ME, Nolan RB, Rittinger WJ: Primary care physicians' attitudes and practices regarding complementary and alternative medicine. J Am Osteopath Assoc 2003;103:597-602.

21 van Haselen RA, Reiber U, Nickel I, Jakob A, Fisher PA: Providing Complementary and Alternative Medicine in primary care: the primary care workers' perspective. Complement Ther Med 2004; 12:6-16.

22 Tindle HA, Davis RB, Phillips RS, Eisenberg DM: Trends in use of complementary and alternative medicine by US adults: 1997-2002. Altern Ther Health Med 2005;11:42-49.

23 Williamson I, Benge S, Moore M, Kumar S, Cross M, Little P: Acute sinusitis: Which factors do FPs believe are most diagnostic and best predict antibiotic efficacy? J Fam Pract 2006;55:789-796.

24 Weber U, Luedtke R, Friese KH, Fischer I, Moeller $\mathrm{H}$ : A non-randomised pilot study to compare complementary and conventional treatments of acute sinusitis. Forsch Komplementärmed Klass Naturheilkd 2002;9:99-104.

25 Unkelbach R, Abholz HH: [Differences between patients of conventional and anthroposophic family physicians]. Forsch Komplementärmed 2006;13: 349-355.

26 Freeman GK, Horder JP, Howie JG, Hungin AP, Hill AP, Shah NC, Wilson A: Evolving general practice consultation in Britain: issues of length and context. BMJ 2002;324:880-882.

27 Martin CM, Banwell CL, Broom DH, Nisa M: Consultation length and chronic illness care in general practice: a qualitative study. Med J Aust 1999;171: $77-81$. 